\title{
Fuzzy Set Qualitative Comparative Analysis (fsQCA) Applied to the Driving Mechanism of Total Factor Productivity Growth
}

\author{
Qibo Diao $\mathbb{D}^{1}$ and Yuanchun Liu $\mathbb{D}^{2}$ \\ ${ }^{1}$ School of Finance and Mathematics, Huainan Normal University, Huainan, Anhui, China \\ ${ }^{2}$ Finance Department, Bengbu University, Bengbu, Anhui, China \\ Correspondence should be addressed to Qibo Diao; diaoqibo1994@163.com
}

Received 15 August 2021; Accepted 18 October 2021; Published 17 November 2021

Academic Editor: Shenggang Li

Copyright (c) 2021 Qibo Diao and Yuanchun Liu. This is an open access article distributed under the Creative Commons Attribution License, which permits unrestricted use, distribution, and reproduction in any medium, provided the original work is properly cited.

\begin{abstract}
With the gradual improvement of fuzzy set qualitative comparative analysis (fsQCA), it is introduced into more and more fields to analyze practical problems. This paper calculates the total factor productivity index and analyzes its development trend based on relevant economic development theories and China's inter-provincial panel data from 1999 to 2019. We use the fsQCA method to study the interaction of factors influencing total productivity in various regions. Two specific paths to improve total factor productivity are obtained, which provide a reference for different areas to improve total factor productivity according to local conditions.
\end{abstract}

\section{Introduction}

China's economy has turned to high-quality development in recent years, and economic growth has become a new normal. With the arrival of Lewis turning point, the shortage of labor in some specific areas is restricting the development of the economy. China's economy urgently needs to be transformed. Romer reveals that total factor productivity (TFP) is the only source of economic growth [1]. It is also widely accepted that factors such as technical progress, efficiency improvement, and returns to scale are all the contributions of TFP to economics. Does China's financial development meet expectations? Is the trend of total factor productivity consistent with the previous study? What is the driving mechanism of the growth of TFP? Trying to answer these questions has become the focus of this article.

The current total factor productivity measurement methods mainly include the Solow residual value method and frontier analysis method. The former is the residual calculation method of TFP proposed by Solow in 1957 [2]. Based on the neoclassical production function, the residual value is obtained after excluding all factor inputs from the total output growth rate, thus reflecting the growth of TFP.
This method is simple and easy to implement, but the assumptions are strict, and the empirical estimation may have significant errors. The frontier analysis method relaxes assumptions, improves accuracy, and decomposes total factor productivity, reflecting the economic growth in technological progress rate, scale efficiency, and technical efficiency [3]. The current mainstream analysis methods include the stochastic frontier production function method (SFA) proposed by Farrell and Charnes in 1957 and the data envelopment analysis method (DEA) proposed by Aigner in 1978. After that, Fare combined the Malmquist index method with data envelopment in 1994, making it the most commonly used analysis method to measure efficiency. Zheng and Xie (2011), Gao Fan (2015), Liu Wei (2018), and other scholars all used the above methods to measure and analyze total factor productivity [4-6].

In recent years, a handful of studies have examined the influencing factor of TFP. Most research studies focus on external factors such as industrial structure, urbanization level, human capital, and government subsidies on total factor productivity [3]. Some scholars empirically analyzed the positive influence mechanism of factor endowment structure, financial development, and technological progress 
on regional TFP and discussed the impact of these factors on total factor productivity [7]. Also, some scholars explained the influence mechanism from the internal structure of TFP and concluded that the growth of TFP of industrial enterprises in China mainly comes from technological progress [8-10].

However, few if any of these studies have explained the growth path of total factor productivity under the combined action of multiple influencing factors. This paper thus attempts to analyze the growth path of TFP when different factors are used as core factors to provide a reference for TFP growth and promote high-quality economic development.

\section{Model and Data}

2.1. DEA-Malmquist Index. The Malmquist index was first proposed by Swedish economist Sten Malmquist in 1953 [11]. Then, Carves applied the idea of scale factor to economic analysis and constructed a distance function to measure productivity index. However, there was no suitable measurement method at that time. Until 1978, the Malmquist index became an important empirical index. The productivity index of Malmquist based on reference technology of $T$ and $T+1$ is as follows:

$$
\begin{aligned}
M^{t} & =\frac{D_{0}^{t}\left(x^{t+1}, y^{t+1}\right)}{D_{0}^{t}\left(x^{t}, y^{t}\right)}, \\
M^{t+1} & =\frac{D_{0}^{t+1}\left(x^{t+1}, y^{t+1}\right)}{D_{0}^{t+1}\left(x^{t}, y^{t}\right)},
\end{aligned}
$$

where $D_{0}^{t}$ is a distance function based on output; $x$ is the input index; and $y$ is the output index. According to the excellent index idea of Fisher, we calculate the geometric average of $M^{t}$ and $M^{t+1}$ to measure the composite productivity index:

$$
\begin{aligned}
M\left(x^{t}, y^{t}, x^{t+1}, y^{t+1}\right) & =\left(M^{t} * M^{t+1}\right)^{1 / 2}=\left(\frac{D_{0}^{t}\left(x^{t+1}, y^{t+1}\right)}{D_{0}^{t}\left(x^{t}, y^{t}\right)} * \frac{D_{0}^{t+1}\left(x^{t+1}, y^{t+1}\right)}{D_{0}^{t+1}\left(x^{t}, y^{t}\right)}\right)^{1 / 2} \\
& =\frac{D_{0}^{t+1}\left(x^{t+1}, y^{t+1}\right)}{D_{0}^{t}\left(x^{t}, y^{t}\right)} *\left(\frac{D_{0}^{t}\left(x^{t+1}, y^{t+1}\right)}{D_{0}^{t+1}\left(x^{t+1}, y^{t+1}\right)} * \frac{D_{0}^{t}\left(x^{t}, y^{t}\right)}{D_{0}^{t+1}\left(x^{t}, y^{t}\right)}\right)^{1 / 2},
\end{aligned}
$$

where $D_{0}^{t+1}\left(x^{t+1}, y^{t+1}\right) / D_{0}^{t}\left(x^{t}, y^{t}\right)$ represents the change of technical efficiency, which indicates the change of possible boundary distance from the decision-making unit to potential optimal production. If the value is greater than 1 , it suggests the improvement of technical efficiency. At the same time, the index can be divided into the change of pure technological efficiency and scale efficiency, and technical efficiency equals the product of pure technological efficiency and scale efficiency. $\left(\left(D_{0}^{t}\left(x^{t+1}, y^{t+1}\right) / D_{0}^{t+1}\left(x^{t+1}, y^{t+1}\right)\right) *\right.$ $\left.\left(D_{0}^{t}\left(x^{t}, y^{t}\right) / D_{0}^{t+1}\left(x^{t}, y^{t}\right)\right)\right)$ indicates the evolution of technical level. If the value is greater than 1 , there will be technical progress. The TFP index equals the product of technology efficiency and technology progress, which measures the change degree of total factor productivity.

2.2. Methodology. Ragin first proposed the fuzzy set qualitative comparative analysis method in 2008 [12]. This method was developed based on QCA. By using the set theory configuration analysis method of Boolean algebra and investigating the sufficient and necessary subset relationship between antecedent conditions and results, it can explore how complex social problems are induced by multiple concurrent causalities as a whole [12]. In recent years, this method has attracted more and more attention and recognition in social science. In organization and management research, QCA provides new ideas and techniques for explaining the complex causality of organizational practice, such as concurrent causality, equivalence, and asymmetry [13-15]. The fsQCA method attempted to establish the logical relationship between causal condition combination and expected results to explain facts and phenomena.

It is assumed that independent variables have an impact on the dependent variable $Y$. In the past, some methods only discussed the result of a single variable on the dependent variable. Still, in the fsQCA, the variables can be combined in pairs or work together to predict the value of the dependent variable $Y$ [16]. Variables need to be calibrated before using fuzzy set analysis.

$$
\text { Calibrate }(x, n 1, n 2, n 3),
$$

where

$$
\begin{aligned}
x & =\text { original data } \\
n_{1} & =\text { complete membership point } \\
n_{2} & =\text { cross membership point } \\
n_{3} & =\text { complete non }- \text { membership point. }
\end{aligned}
$$

After the calibration, the data are transformed into fuzzy membership scores in fuzzy sets between 0 and 1 to generate a truth table. Finally, the reliability of the results is discussed according to the values of consistency and coverage. Consistency corresponds to the set theory relationship expressed in the case and solution [17]. Coverage is the relative importance of different paths to the results: 


$$
\begin{aligned}
\text { consistency: }\left(X_{i} \leq Y_{i}\right) & =\frac{\sum \min \left(X_{i}, Y_{i}\right)}{\sum\left(X_{i}\right)}, \\
\text { coverage: }\left(X_{i} \leq Y_{i}\right) & =\frac{\sum \min \left(X_{i}, Y_{i}\right)}{\sum\left(Y_{i}\right)},
\end{aligned}
$$

where $X_{i}$ represents the member score of the case $i$ in set $X$ and $Y_{i}$ means the member score of the case $i$ in the result condition in set $Y$. Generally speaking, if the consistency value is greater than 0.8 , it can be considered that the effect of this path to explain the case is good. The framework of the fsQCA method is shown in Figure 1.

\subsection{Variable Selection}

2.3.1. Explained Variable: Total Factor Productivity. The Solow residual value method is simple and easy to implement. Total factor productivity is obtained by calculating the output growth rate and subtracting the factor growth rate. The frontier analysis method decomposes the TFP from technical efficiency, technological progress rate, pure technical efficiency, and scale efficiency. They reflect the actual situation of economic growth. In comparison, the traditional production function method is based on stricter assumptions, leading to significant deviations in actual estimation results. The frontier analysis method relaxes the assumptions and helps improve the accuracy of estimation. This paper uses the DEA-Malmquist index method to measure the TFP index.

The data period in this article is from 1998 to 2019, the output indicator is the gross domestic product (GDP) of each province in China (note: to keep the time and region dimension of data consistent with the following, the relevant data of Tibet are not selected here), and the input indicator, capital stock, is calculated using the total investment in fixed assets, referring to Coe [18] and Zhang [19]. At first, we calculate the capital stock with 1997 as the base period according to $K_{i 0}=I_{i 0} /(g+\delta)$, assuming that the economic depreciation rate $\delta$ is $6 \%$ [20], where $I_{i 0}$ is the total fixedasset investment in the base period and gis the economic growth rate of the current year. Subsequently, we use the perpetual inventory method to calculate the capital stock of 30 provinces (region or city) from 1998 to 2019 . The specific calculation formula is as follows:

$$
K_{i t}=I_{i t}+(1-\delta) K_{i t-1} .
$$

The labor input index selects the number of employees at the end of the year. The primary data come from the China National Bureau of Statistics and the provincial statistical yearbooks.

We use the software of DEAP (version 2.1) to calculate the TFP index. The total factor productivity and related decomposition data from 1999 to 2019 are shown in Table 1.

As shown in Table 1, only six regions' TFP index is less than 1 , and total factor productivity in most areas shows a positive growth trend. The results show that since 1999-2019, the internal driving force of China's total factor productivity growth comes from technological progress and the improvement of technical efficiency. However, as shown in Figure 2, we can see that the technology progress index is greater than TFP index in only a few areas, so we can conclude that the advancement of technological efficiency is much more significant than technological progress.

\subsubsection{Conditional Variable}

Financial Development. There are many indicators to measure financial development, and most of them use the ratio of deposit and loan balance to GDP. This article divides financial development into two dimensions: development scale (SFD) and development efficiency (EFD). The ratio of the loan balance to GDP is used to measure the scale of financial development. Financial development efficiency is the allocation of financial resources. Referring to the inputoutput efficiency, we adopt the ratio of new loans to the added value of the financial industry.

The Level of Foreign Investment (FIL). This article selects the proportion of total investment of foreign-invested enterprises to GDP to measure the level of foreign investment. It is converted at the exchange rate of RMB and US dollars in that year.

The Level of Government Expenditure (GEL). Generally speaking, the more the government purchases, the greater the total demand will be. Still, because the crowding-out effect will hinder private investment and harm economic growth, this article uses the general budget expenditure of local finances in each region to the regional GDP to measure government fiscal expenditure.

The Intensity of Technological Innovation (TII). Science and technology are the primary productive forces, and endogenous growth theory also believes that $\mathrm{R} \& \mathrm{D}$ is a vital driving force for technological progress. This article selects the number of patent applications accepted per 10,000 people as the proxy variable.

The descriptive statistical results of each variable are shown in Table 2 . The average value of the TFP index is only 1.1597, which means that the TFP had positive growth in 2019. The maximum value of the index is 1.328 , and the minimum value is 0.966 . Among the conditional variables, the two variables of financial development efficiency and technological innovation intensity have significant regional differences, reflecting the contrasts of development levels in different regions. Figure 3 shows the scatter plot of conditional variables. It can be found that the more developed the region is, the higher TII and SFD will be. Besides, the relationship between financial development efficiency and financial development scale changes in the opposite direction.

\section{Fuzzy Set Analysis}

3.1. Variable Calibration. The QCA method is based on set theory. Before the discussion, it is necessary to calibrate the 


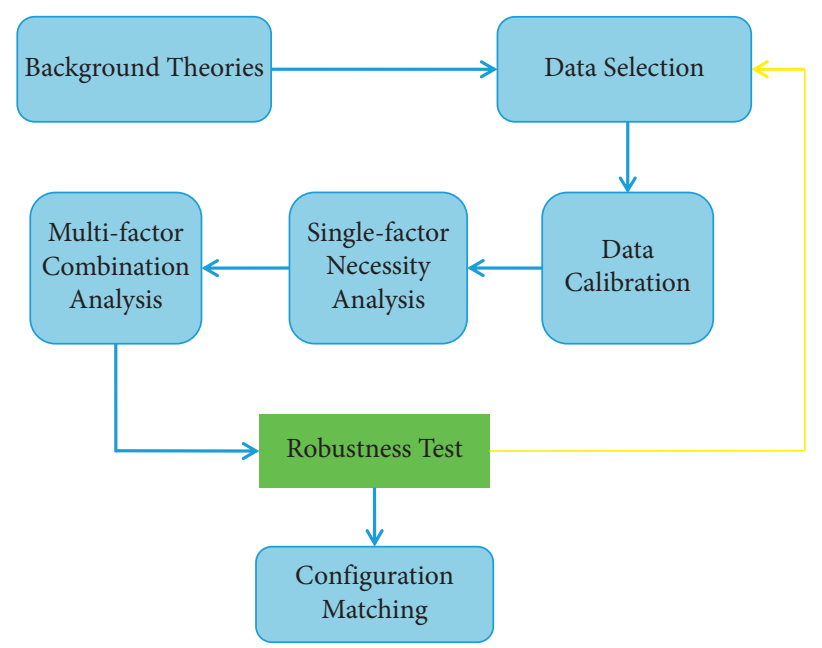

Figure 1: Process of the fsQCA method.

TABLE 1: Total factor productivity index and its decomposition (mean value).

\begin{tabular}{|c|c|c|c|c|c|}
\hline Region & $\begin{array}{c}\text { Technical efficiency } \\
\text { index }\end{array}$ & $\begin{array}{c}\text { Technology progress } \\
\text { index }\end{array}$ & $\begin{array}{l}\text { The pure technical efficiency } \\
\text { index }\end{array}$ & $\begin{array}{l}\text { Scale efficiency } \\
\text { index }\end{array}$ & Malmquist index of TFP \\
\hline Beijing & 1.024952 & 1.01281 & 1.010857 & 1.011857 & 1.002238 \\
\hline Tianjin & 1.025333 & 1.014429 & 1.010952 & 1.010476 & 1.005095 \\
\hline Hebei & 1.023 & 1.024286 & 1.007476 & 1.010762 & 1.00881 \\
\hline Shanxi & 1.018952 & 1.026571 & 1.007238 & 1.010095 & 1.018762 \\
\hline Neimenggu & 1.01781 & 0.977619 & 1.005286 & 1.007857 & 0.964952 \\
\hline Liaoning & 1.015476 & 0.979429 & 1.006286 & 1.007286 & 0.971381 \\
\hline Jilin & 1.014857 & 0.999286 & 1.005952 & 1.004524 & 0.998476 \\
\hline Heilongjiang & 1.015286 & 1.001571 & 1.006667 & 1.004429 & 0.998333 \\
\hline Shanghai & 1.014667 & 1.012286 & 1.008048 & 1.003095 & 1.013905 \\
\hline Jiangsu & 1.005333 & 1.01419 & 1.000476 & 1.004333 & 1.011476 \\
\hline Zhejiang & 1.007429 & 1.02481 & 1.003286 & 1.00319 & 1.021095 \\
\hline Anhui & 1.006952 & 1.016952 & 1.00381 & 1.003524 & 1.014286 \\
\hline Fujian & 1.003381 & 1.022 & 1.000333 & 1.004333 & 1.014571 \\
\hline Jiangxi & 1.007095 & 1.013095 & 1.00381 & 1.002762 & 1.00881 \\
\hline Shandong & 1.004381 & 1.021476 & 1.001952 & 1.002 & 1.018619 \\
\hline Henan & 1.005381 & 1.01681 & 1.003619 & 1.001286 & 1.021048 \\
\hline Hubei & 1.007905 & 1.023714 & 1.005476 & 1.001048 & 1.032476 \\
\hline Hunan & 1.009286 & 1.019714 & 1.006952 & 1.000619 & 1.034 \\
\hline Guangdong & 1.011952 & 0.985381 & 1.009 & 1.000952 & 1.002524 \\
\hline Guangxi & 1.011571 & 0.98419 & 1.008143 & 1.000667 & 1.000476 \\
\hline Hainan & 1.026524 & 0.970714 & 1.014381 & 1.010952 & 1.009238 \\
\hline Chongqing & 1.019238 & 0.969095 & 1.009048 & 1.009667 & 0.99981 \\
\hline Sichuan & 1.02719 & 0.978 & 1.011619 & 1.013952 & 1.018952 \\
\hline Guizhou & 1.024143 & 0.982048 & 1.012286 & 1.011476 & 1.020286 \\
\hline Yunnan & 1.02019 & 0.993619 & 1.005857 & 1.016905 & 1.026476 \\
\hline Shaanxi & 1.017095 & 1.002952 & 0.998143 & 1.01719 & 1.033048 \\
\hline Gansu & 1.019619 & 0.980571 & 0.997333 & 1.01919 & 0.999857 \\
\hline Qinghai & 1.022238 & 0.986524 & 1.004667 & 1.017905 & 1.00519 \\
\hline Ningxia & 1.031476 & 0.993714 & 1.007571 & 1.024667 & 1.014286 \\
\hline Xinjiang & 1.038 & 1.005476 & 1.005714 & 1.027619 & 1.023143 \\
\hline Mean value & 1.016557 & 1.001778 & 1.006075 & 1.008821 & 1.010387 \\
\hline
\end{tabular}

data and collect the data between 0 and 1 . The specific method uses anchor points to determine each group of data qualitatively and calibrate each group of variables to a fuzzy set belonging to $0-1$ by using three critical values: complete membership point, cross membership point, and complete non-membership point. Referring to the practice of $\mathrm{Du}[14]$, this paper selects the 95 th percentile, 50th percentile, and 5 th percentile as the anchor point to calibrate the data. The calibration anchor points of each variable are shown in Table 3.

After calibration, according to the calculation principle of Boolean algebra, we combine each conditional variable 


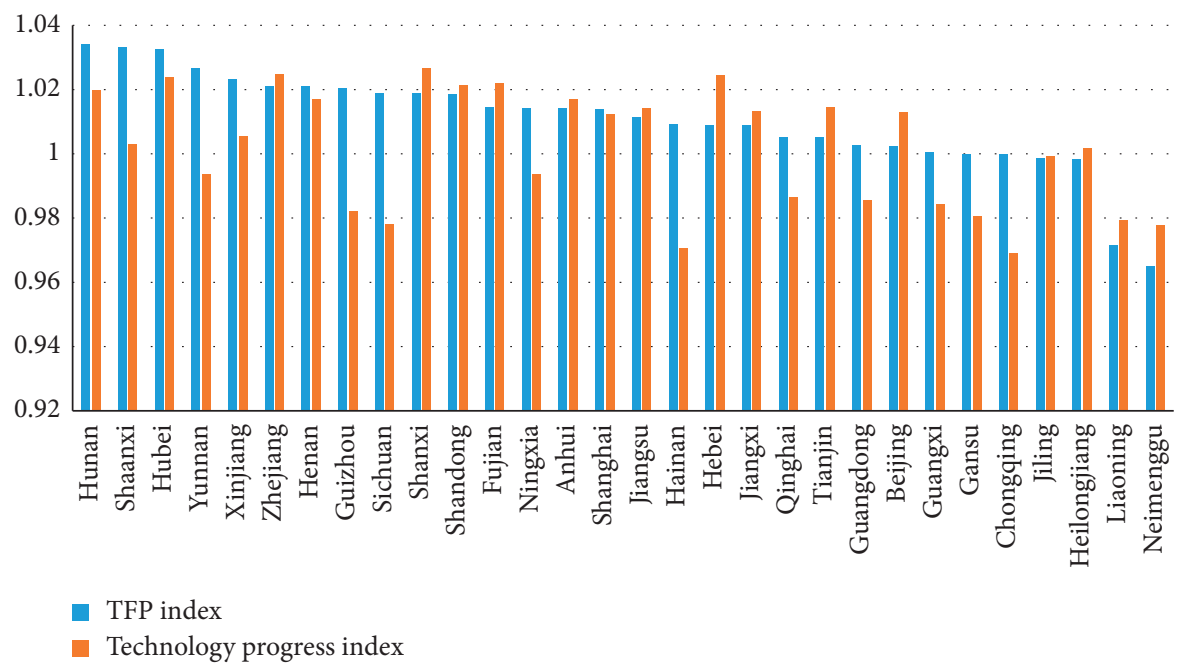

Figure 2: Comparison of TFP index and technology progress index in different regions.

TABLE 2: Summary statistics of all the variables.

\begin{tabular}{|c|c|c|c|c|c|}
\hline Variables & Observations & Mean & Standard deviation & Max & Min \\
\hline TFP & 30 & 1.1597 & 0.0897 & 1.328 & 0.966 \\
\hline SFD (loan balance/GDP) & 30 & 1.6160 & 0.4035 & 2.5713 & 1.0361 \\
\hline EFD (new loan/added value of financial industry) & 30 & 2.1223 & 0.7669 & 3.5224 & 0.2196 \\
\hline FIL (total investment of foreign-invested enterprises/GDP) & 30 & 0.5436 & 0.4560 & 1.7542 & 0.1238 \\
\hline GEL (budget expenditure/GDP) & 30 & 0.2651 & 0.1092 & 0.6337 & 0.1200 \\
\hline TII (number of patent applications accepted/permanent population) & 30 & 27.2623 & 25.5787 & 103.2479 & 5.7722 \\
\hline
\end{tabular}

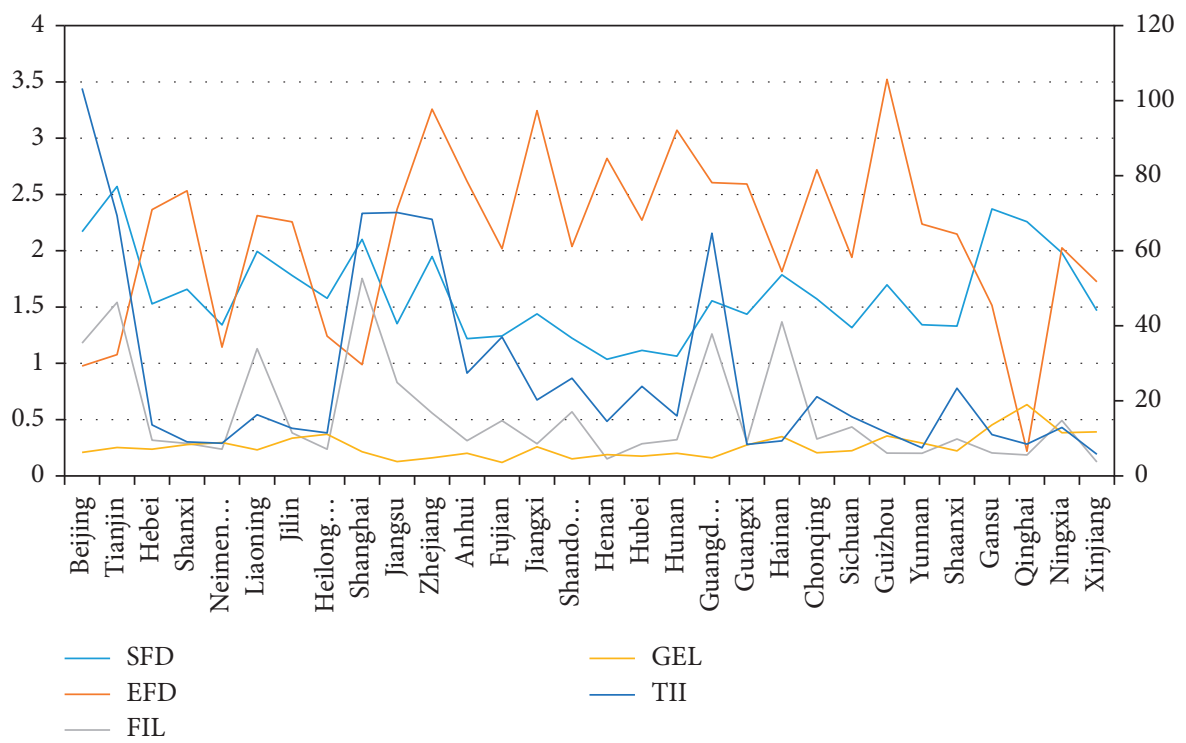

FIGURE 3: Scatter plot of conditional variables. Note: TII corresponds to the secondary axis.

and set the acceptable combination number to 1 and the consistency to 0.8 . Finally, we calculate the truth table (as shown in Table 4).

3.2. Necessity Analysis. After calibration, the necessary conditions will be eliminated in the process of forming the reduced solution. Therefore, it is essential to check the necessity of each condition variable and determine whether the condition variable is the necessary condition of the result. According to previous studies, it is customary to use the consistency of necessary conditions to judge whether it is an essential condition and to what extent the fuzzy set of the result is a subset of the conditional fuzzy set. Ragin [12] believes that consistency can be significant only when it reaches more than 0.9 , indicating that independent variables 
TABLE 3: Calibration anchor point for each variable.

\begin{tabular}{|c|c|c|c|c|c|}
\hline \multirow[b]{2}{*}{ Variables } & \multirow[b]{2}{*}{ Dimension } & \multirow[b]{2}{*}{ Index } & \multicolumn{3}{|c|}{ Anchor point } \\
\hline & & & Complete membership point & Cross membership point & $\begin{array}{l}\text { Complete non- } \\
\text { membership point }\end{array}$ \\
\hline \multirow{5}{*}{$\begin{array}{l}\text { Conditional } \\
\text { variables }\end{array}$} & Elements of financial & SFD & 2.46158 & 1.54185 & 1.05102 \\
\hline & development & EFD & 3.37684 & 2.24703 & 0.636 \\
\hline & $\begin{array}{c}\text { Elements of } \\
\text { international } \\
\text { cooperation }\end{array}$ & FIL & 1.63713 & 0.32501 & 0.13877 \\
\hline & Elements of policy & GEL & 0.53444 & 0.23434 & 0.12408 \\
\hline & $\begin{array}{l}\text { Elements of } \\
\text { technology }\end{array}$ & $\begin{array}{l}\text { TII (item/ } \\
10000 \\
\text { persons) }\end{array}$ & 85.05373 & 15.86548 & 6.7058 \\
\hline Result variable & & TFP & 1.31865 & 1.1425 & 0.99515 \\
\hline
\end{tabular}

TABLE 4: Coding results.

\begin{tabular}{|c|c|c|c|c|c|c|c|}
\hline SFD & EFD & FIL & GEL & TII & Number & TFP & Raw consistency \\
\hline 1 & 0 & 1 & 0 & 1 & 2 & 1 & 0.984014 \\
\hline 1 & 0 & 1 & 1 & 1 & 1 & 1 & 0.975207 \\
\hline 1 & 1 & 1 & 1 & 0 & 1 & 1 & 0.967213 \\
\hline 1 & 1 & 1 & 0 & 1 & 2 & 1 & 0.951699 \\
\hline 1 & 0 & 1 & 1 & 0 & 2 & 1 & 0.948399 \\
\hline 0 & 1 & 0 & 1 & 1 & 1 & 1 & 0.945455 \\
\hline 0 & 1 & 0 & 1 & 0 & 2 & 1 & 0.920896 \\
\hline 1 & 1 & 0 & 1 & 0 & 2 & 1 & 0.919328 \\
\hline 0 & 0 & 0 & 1 & 0 & 2 & 0 & 0.893023 \\
\hline 0 & 0 & 1 & 0 & 0 & 1 & 0 & 0.884956 \\
\hline 0 & 1 & 0 & 0 & 0 & 1 & 0 & 0.854331 \\
\hline 0 & 1 & 1 & 0 & 1 & 1 & 0 & 0.84233 \\
\hline 0 & 1 & 0 & 0 & 1 & 2 & 0 & 0.830925 \\
\hline 0 & 0 & 1 & 0 & 1 & 2 & 0 & 0.780731 \\
\hline 1 & 0 & 0 & 1 & 0 & 3 & 0 & 0.76155 \\
\hline
\end{tabular}

are necessary results. Table 5 lists the calculation results of the necessity test of each conditional variable. It can be seen that the consistent impact of the five-dimensional elements on the growth of TFP is less than 0.9. The single variable is not necessary for the result, indicating that a single-dimensional component does not determine the development of total factor productivity.

3.3. Configuration Analysis. We use software of fsQCA (version 30) to analyze the standard of the calibrated truth table, and we can get three schemes with different conditions, namely, complex solution, economical solution, and intermediate solution. The complex solution is a path reflected by all conditional variables without simplification and the logical remainder, so its universality is not high. After simplifying the result, the parsimonious solution is the decisive influence path; the intermediate solution is between the two, and the edge condition is added based on the reduced solution, which is universal. The configuration results obtained after standardized analysis are shown in Table 6. The overall consistency is 0.8958 , and the coverage is 0.698363 . The results meet the qualitative analysis standards proposed by Woodside and Zhang [21], and the conclusions are representative.
According to the core conditions in 4 configurations in Table 6, Figure 4 shows 2 significant paths to achieve high TFP growth.

(1) Finance-Policy Correlation Driven. According to configurations 1 and 2, high financial development and policy factors are the core conditions for total productivity growth. The results show that for some inland areas, such as Hebei, Guizhou, and Jilin, even if the terms of foreign trade are not prominent, we can still effectively promote the improvement of total factor productivity by improving fiscal expenditure support and increasing financial aid. Among them, financial support depends more on the progress of fund use efficiency.

(2) Finance-Investment Correlation Driven. Configuration 3: SFD $* \sim \mathrm{EFD} * \mathrm{FIL} * \mathrm{GEL}$, shows that higher financial development scale factors, international factors, policy factors, and non-high financial development efficiency are the sufficient conditions for higher total factor productivity, among which financial development scale and foreign investment level are the core conditions. It shows that even if the financial development efficiency is low and the policy fiscal expenditure level is not prominent, the regional 
TABle 5: Necessity test results of conditional variables.

\begin{tabular}{lcccc}
\hline & \multicolumn{2}{c}{ Growth of TFP } & \multicolumn{2}{c}{ Non-growth of TFP } \\
& Consistency & Coverage & Consistency & Coverage \\
\hline SFD & 0.710957 & 0.786212 & 0.574363 & 0.564763 \\
$\sim$ SFD & 0.606423 & 0.615729 & 0.782578 & 0.706522 \\
EFD & 0.651133 & 0.701492 & 0.683428 & 0.654681 \\
$\sim$ EFD & 0.679471 & 0.707077 & 0.688385 & 0.636959 \\
FIL & 0.735516 & 0.801097 & 0.613314 & 0.593964 \\
$\sim$ FIL & 0.627204 & 0.645914 & 0.794618 & 0.727627 \\
GEL & 0.670025 & 0.736842 & 0.640227 & 0.626039 \\
$\sim$ GEL & 0.65995 & 0.673522 & 0.730878 & 0.663239 \\
TII & 0.622166 & 0.72754 & 0.622521 & 0.647275 \\
$\sim$ TII & 0.698363 & 0.675396 & 0.73796 & 0.634592 \\
\hline
\end{tabular}

TABLE 6: Configuration results of higher total factor productivity.

\begin{tabular}{lcccc}
\hline Configurations & 1 & 2 & 3 & $\bullet$ \\
\hline SFD & $\otimes$ & $\cdot$ & $\otimes$ \\
EFD & $\bullet$ & $\bullet$ & $\bullet$ \\
FIL & $\otimes$ & $\bullet$ & $\cdot$ \\
GEL & $\bullet$ & 0 & 0.956587 & $\bullet$ \\
TII & & 0.3877909 & 0.402393 \\
Raw consistency & 0.907381 & 0.0163728 & 0.043451 \\
Coverage & 0.394836 & & 0.962079 \\
Unique consistency & 0.0843829 & & 0.116499 \\
Solution consistency & 0.8958 & & \\
Solution coverage & 0.698363 & & \\
\hline
\end{tabular}

Note. $\bullet$ indicates the core conditions with high element level; $\cdot$ indicates edge conditions with high element level; $\otimes$ indicates that the element level is low; and blank indicates that the level of elements does not affect the results.

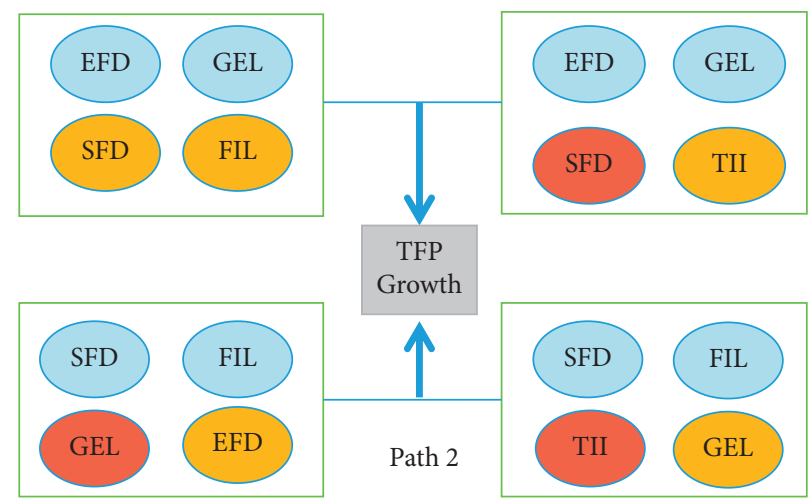

FIgURe 4: Paths to achieve high TFP growth. Note: the blue box represents the core conditions, the red box represents edge conditions, and the yellow box means that the element level is low.

total factor productivity can still be improved by increasing the total financial credit expenditure and enhancing foreign direct investment. Typical areas through this path are Hainan, Tianjin, and so on. Configuration 4: $\mathrm{SFD} * \mathrm{FIL} * \sim \mathrm{GEL} * \mathrm{TII}$, also shows the importance of the financial development scale and foreign direct investment level to promote total factor productivity. Unlike configuration 3, these regions (Beijing, Shanghai, Zhejiang, etc.) emphasize the importance of scientific and technological innovation elements more than policy elements.

\section{Conclusion}

Based on the annual panel data of 30 provinces in China from 1999 to 2019, this paper first calculates the TFP growth index in various regions of China. Then, we use the fuzzy set qualitative comparative analysis method to study the influence of different conditional variables on total factor productivity from the overall perspective of configuration thinking. The conclusion shows that the internal driving force of China's total factor productivity growth comes from both technological progress and the improvement of technical efficiency. The advancement of technological efficiency 
is much more significant than technological progress. Second, due to the different inputs of various factors, there are substantial differences in total factor productivity growth in multiple regions. Third, through configuration analysis, the core factors and two paths to promote the development of total factor productivity are obtained. Different areas can take appropriate countermeasures and suggestions according to their conditions.

\section{Data Availability}

The data used to calculate the TFP index are collected from the China National Bureau of Statistics website (http://www. stats.gov.cn/tjsj/). The data used to support the findings of this study are also available from the corresponding author upon request.

\section{Conflicts of Interest}

The authors declare that there are no conflicts of interest regarding the publication of this paper.

\section{Acknowledgments}

This study was supported by research projects of Huainan Normal University (no. 2020XJYB024).

\section{References}

[1] P. M. Romer, "Increasing returns and long-run growth," Journal of Political Economy, vol. 94, no. 5, pp. 1002-1037, 1986.

[2] R. M. Solow, "Technical change and the aggregate production function," The Review of Economics and Statistics, vol. 39, no. 3, pp. 312-320, 1957.

[3] P. Yan and B. Wang, "Technical efficiency, technological progress and productivity growth: an empirical analysis based on DEA," Economic Research, vol. 12, pp. 55-65, 2004.

[4] B. Zheng and Z. Xie, "Research on China's regional total factor productivity based on low-carbon economy," Economic Developments, vol. 10, pp. 38-41, 2011.

[5] G. Fan, "The evolutionary trend and influencing factors of my country's regional agricultural total factor productivity: empirical analysis based on inter-provincial panel data," Quantitative Economics and Technical Economics, vol. 5, pp. 3-19+53, 2015.

[6] W. Liu and L. Zhang, "Resource allocation, industrial structure and total factor productivity: an analysis based on the real business cycle model," Economic Theory and Economic Management, vol. 9, pp. 5-22, 2018.

[7] M. Chen, X. Zhang, C. Zhong, and Y. Liu, "Regional differences and influencing factors of total factor productivity growth in the Yangtze River Economic Belt," Comparison of Economic and Social Systems, vol. 2, pp. 162-172, 2018.

[8] Z. Chen and Z. Zhang, "A comparative study on the total factor productivity of industrial enterprises of different ownership in my country-an empirical analysis based on malmquist index," Industrial Technology Economy, vol. 1, pp. 13-19, 2011.

[9] C. Yin, G. Li, and Y. He, "The dynamic evolution of the regional gap of agricultural total factor productivity and its growth distribution: an empirical study based on non-parametric estimation methods," Journal of Huazhong
Agricultural University (Social Science Edition), vol. 2, no. 136, pp. 38-46+135, 2016.

[10] M.. Cao, "Research on the time evolution and regional differences of agricultural total factor productivity: an empirical analysis based on Jiangsu Province," Science and Technology and Industry, vol. 6, pp. 14-16+126, 2017.

[11] S. Malmquist, "Index numbers and indifference surfaces," Trabajos de Estatistica, vol. 4, pp. 209-242, 1953.

[12] C. C. R. Ragin, Social inquiry: Fuzzy Sets and Beyond, University of Chicago Press, Chicago, IL, USA, 2008.

[13] S. Fainshmidt, M. A. Witt, R. V. Aguilera, and A. Verbeke, "The contributions of qualitative comparative analysis (QCA) to international business research," Journal of International Business Studies, vol. 51, no. 4, pp. 455-466, 2020.

[14] Y. Du and L. Jia, "Configuration perspective and qualitative comparative analysis (QCA): a new way of management research," Management World, vol. 6, pp. 155-167, 2017.

[15] E. J. Douglas, D. A. Shepherd, and C. Prentice, "Using fuzzyset qualitative comparative analysis for a finer-grained understanding of entrepreneurship," Journal of Business Venturing, vol. 35, no. 1, Article ID 105970, 2020.

[16] P. C. Fiss, "A set-theoretic approach to organizational configurations," Academy of Management Review, vol. 32, no. 4, pp. 1180-1198, 2007.

[17] P. C. Fiss, "Building better causal theories: a fuzzy set approach to typologies in organization research," Academy of Management Journal, vol. 54, no. 2, pp. 393-420, 2011.

[18] R. Levine, "Financial development and economic growth: views and agenda," Journal of Economic Literature, vol. 35, pp. 688-726, 1997.

[19] J. Zhang, "Changes in China's total factor productivity: 19521998," World Economic Papers, vol. 2, pp. 17-24, 2003.

[20] Young Alwyn, Gold into Base Metals: Productivity Growth in the People's Republic of China during the Reform Period, National Bureau of Economic Research, Cambridge, MA, USA, Article ID 7856, 2000.

[21] A. G. Woodside and M. Zhang, "Lagged impacts of reforms of government regulations of business on nations' gross domestic product," Corporate Board: Role, Duties and Composition, vol. 9, no. 2, pp. 40-53, 2013. 